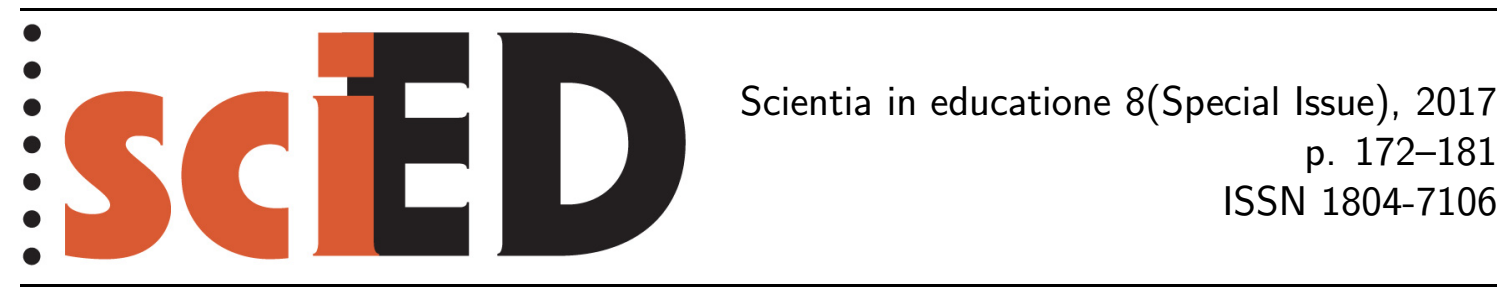

\title{
Development of Interest in Particle Physics as an Effect of School Events in an Authentic Setting
}

\author{
Kerstin Gedigk, Michael Kobel, Gesche Pospiech
}

\begin{abstract}
The Particle Physics Masterclasses are events offered by the "Netzwerk Teilchenwelt", a German network of particle physicists, students and teachers with the intention to make original data from CERN available for own measurements of students. These events were evaluated in 2011/2012. The investigation deals with their effect on the interest development of the youth participants, especially in particle physics. With a focus on the role of different event properties, it can be shown that besides the perceived challenge and comprehension, also authenticity is an important factor for the students' interest development.
\end{abstract}

Key words: interest, evaluation study, Masterclasses, particle physics. 


\section{INTRODUCTION}

The aim of physics education consists not only of teaching the physical contents, but also to a large extent of giving an insight into the process of physics research, into recent research topics and into the fundamental nature of physics and thereby developing the interest of students in physics. These objectives strongly correspond to the aims of the 'Particle Physics Masterclasses'. But it is also well known that "investigations in different countries showed, that the interest in mathematics and in science subjects (...) in the secondary schools decreases" severely (Krapp, 2006: p. 288). How masterclass events and especially the authentic setting of these events have an effect on this interest development of high school students is one of the main questions which should be answered by an evaluation study.

\section{The "NetzWERK TeIlChenWELT"}

The so called "Particle Physics Masterclasses" are offered by the German "Netzwerk Teilchenwelt" (English: Network Particle World) including 24 German particle physics research institutes and $\mathrm{CERN}^{1}$. It is a network between scientists, high school students and teachers. It was founded in 2010 inspired by the "International Hands On Particle Physics Masterclasses", with the idea, to open these appreciated annual events (see e.g. Johansson et al., 2007: p. 640) to more students, all over Germany and throughout the year. Another main concept to bring this network to life was to create a community in which interested students, teachers and particle physicists can be in an active exchange about particle physics, beyond just coming in contact with each other at a one-time event.

The network offers students and teachers the participation in 4 ascending levels. For the school students these different levels are shown in Figure 1. The Particle Physics Masterclasses themselves form the basic level of the program. If the students are interested in obtaining a deeper insight into particle physics beyond participation in a Masterclass they can join the higher levels. The possible activities range from transferring their knowledge about particle physics to conducting own research projects linked to (astro-) particle physics. For teachers a similar 4-level program is made available by the network. Further information about this network can be found at Gedigk, Glück \& Kobel (2011).

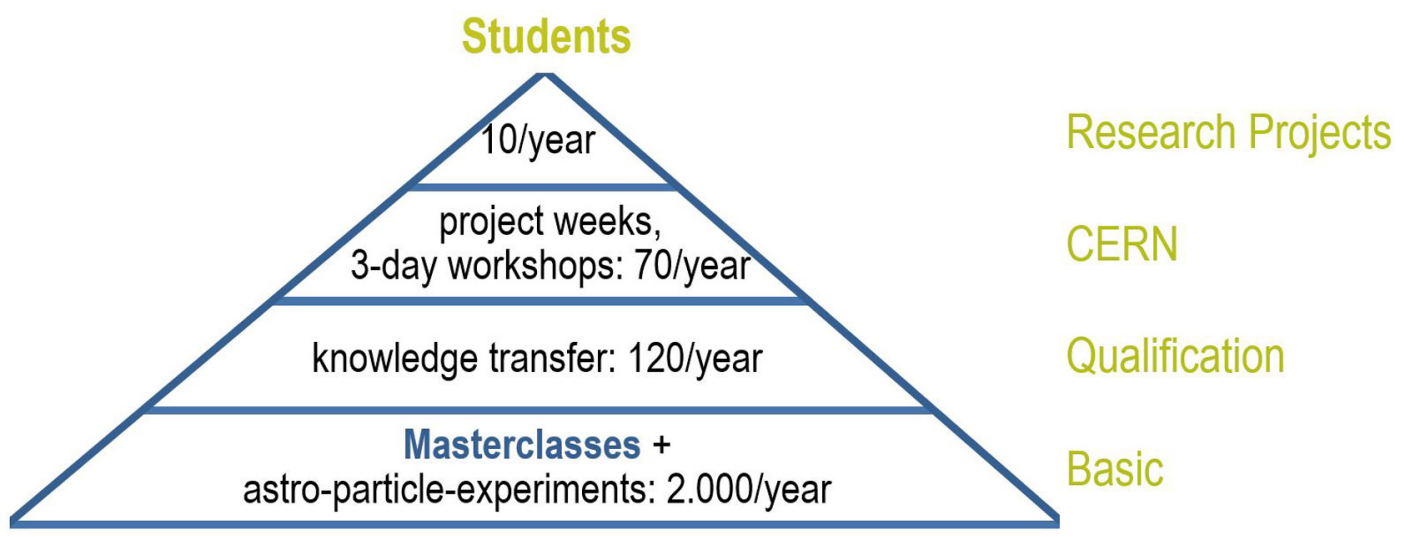

Figure 1: The 4-level programm of "Netzwerk Teilchenwelt". At each level the typical number of participating students is given

\footnotetext{
${ }^{1}$ European Organization for Nuclear Research (near Geneva/Switzerland).
} 


\section{The Particle Physics Masterclasses}

The Particle Physics Masterclasses mostly take place in schools and last between 4 to 6 hours. The facilitators of these events are in most cases young particle physicists, e.g. PhD or Master students. During a Masterclass the scientists give an introduction into particle physics research, e.g. in the "Standard Model of Particle Physics", how the research community works together, which questions should be answered by the actual research, etc. Afterwards the young participants get an introduction how to visually identify particles from their traces in the detector. After an introductory exercise the participants make own measurements with original data from CERN. The students work in pairs to classify 50 to 100 events into various categories. Then the results of the groups are combined and discussed. With statistical methods they arrive at fundamental results which can be compared with predictions of the "Standard Model of Particle Physics".

There are two different kinds of data offered for the Particle Physics Masterclasses: one from CERN's Large Electron Positron Collider (LEP), which was used from 1989 to 2000 and another from the Large Hadron Collider (LHC), which has been in operation since 2010 at CERN. More information about these measurements can be found at (Bilow et al., 2011).

\section{The Aims of The Masterclasses AND THEIR AUthentiC SETTING}

The overarching aim of the Masterclasses is to give an insight into the actual particle physics research in an authentic setting. Another goal is to stimulate the interest of individual students to voluntarily join the higher levels of the network program. Although the Masterclasses take place in schools there are different factors which create an authentic learning environment for the participants. Besides the contact with real scientists there is also the measurement with original data from CERN and the work with graphical visualisation software, which is very close to the one used at CERN. Moreover, guided by the scientists, the students use similar methods to interpret and compare their results with the predictions within the Standard Model.

\section{RESEARCH QUESTIONS}

In the evaluation study it is investigated, if the authentic setting of this one-day event is suitable to influence the interest of students: Are students' interests in physics as well as in particle physics fostered by a Masterclass participation? Can longterm effects be seen? Are there any differences noticed in the interest development between different participant groups (e.g. gender, age, type of school, etc.)? Which event properties are related to interest changes? Can factors be identified, which are crucial for a positive perception of the events? Moreover the evaluation study, which is presented below, makes it possible to say something about the increase in the participants' knowledge and to compare the Masterclasses' effects with results of other recent studies.

\section{The EVALUATION STUDY}

The evaluation study mainly deals with the students' interest. The person-objecttheory by Krapp creates the basis for the current investigation: "Interest designates a relationship of particular importance between a person and an object (...)" (Krapp, 1992: p. 307). The more often and the more intensive a person deals with the 
object the more stable this relationship becomes. Furthermore, the development of this relationship also depends on the situation or the context in which the person is operating with the object (Krapp, 1992: p. 308). In educational research there is an established distinction between the students' interest in the school subject "physics" and in the special physical topics (e.g. Hoffman, Häußler \& Lehrke, 1998: p. 19). For the special interests there are three different dimensions identified: the learning content, the context in which the content appears and the activities which can be connected to the topic (Hoffman, Häußler \& Lehrke, 1998: p. 26).

To measure changes in the students' interests the evaluation study is structured in a pre- post- follow-up design, which means that the participants were evaluated at the beginning, at the end of the Masterclass and again after a 6 to 8 week period. With the follow-up evaluation the sustainability of the Masterclasses can be investigated.

\section{DESCRIPTION OF THE QUestionnaires}

Based on this theoretical basis and recent results on informal out-of-school learning environments (e.g. Engeln, 2004; Pawek, 2009), the questionnaires were developed. Figure 2 shows a selection of variables.

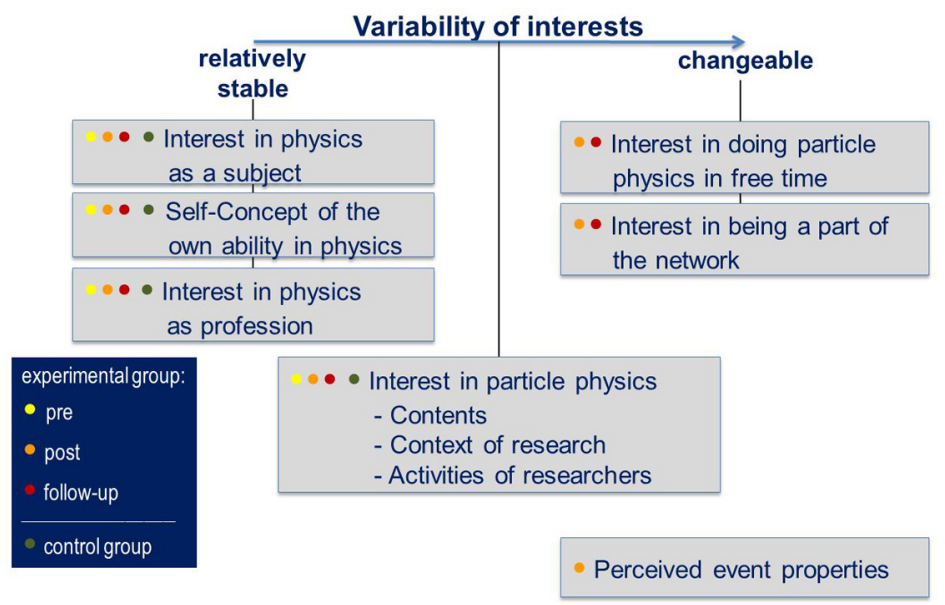

Figure 2: Selection of evaluated variables with the assumed stability

Because particle physics only plays a small role in the German school curricula, the special interest in this topic is assumed to be influenceable. For joining the higher levels in the network program beyond attending a Masterclass, the interest in doing particle physics in free time and in being a part of the network are the crucial variables.

Although the Self-Concept in physics does not directly belong to the interest variables, it is assumed to be relatively stable. Like the interest in physics as a subject and the interest in physics as profession it was created over several years of physics education.

For the questionnaires, which were piloted before, items with a 5-point Likert scale were used. Examples of the items and the computed internal-consistency coefficients (Cronbach's alpha) of the variables can be seen in the tables 3 and 4 in the annex. 
The evaluation study was conducted from October 2011 until May 2012 in 25 Masterclasses with about 500 students ("experimental group"). Additionally a "control group" has been evaluated, i.e. high school students who did not take part in a Masterclass.

Groups of participants

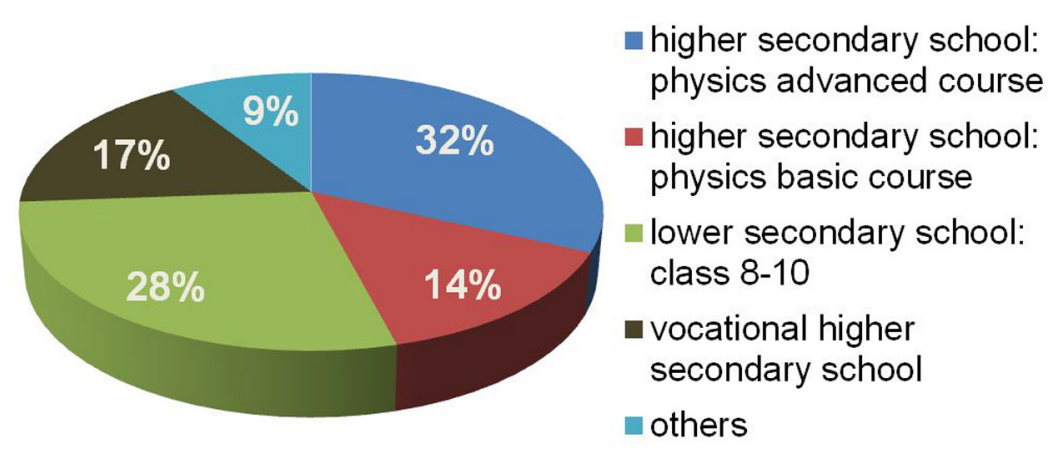

Figure 3: Participants of the experimental group

The "experimental group" consists of four main groups: students of the higher secondary schools (class 11 to 13) divided into the physics advanced and the physics basic course, students who visit the lower secondary school mainly in class 10 and older students who attend a vocational higher secondary school (see Figure 3). About 40 students of the experimental group attend another school form. Excluded were about 40 participants of the study, which already had attended a Masterclass before the evaluation. A fifth of the experimental group is female. The evaluation was conducted in 8 LEP- and 17 LHC-Masterclasses.

\section{COMPARISONS BETWEEN THE EXPERIMENTAL AND THE CONTROL GROUP}

For the comparison between the "experimental group" and the "control group" an analysis of variance with repeated measurements is used. Figure 4 shows selected results for participants attending class 10 of lower secondary schools- results of the higher classes are still under study. In these comparisons just students are included, who participated in a Masterclasses with their whole class, implying that the students in experimental group as well as in control group are not selected. Concerning these analyses of variance only the interaction effects between group and time are interesting, because these say something about the effect of the Masterclasses (Rudolf \& Müller, 2012: p. 121). The separate effects of time and group on the mean are given only for information in the following figures.

For quantifying an effect size we calculate in a variance analysis the fraction $\eta^{2}$ of the total variance that is attributed to the effect (Rudolf \& Müller, 2012: p. 115). For the interest in physics as subject the calculated effect size $\eta^{2}$ shows a small positive short-term effect but no long-term effect (Bortz \& Döring, 2006: p. 606). No effects whatsoever were seen for the class 10 students for the Self-Concept and the interest in physics as profession. The analysis of the amount of the students' interest in particle physics, e.g. in the contents (see Figure 4), show no short-term effects but small negative long-term effects. These developments correspond to the 


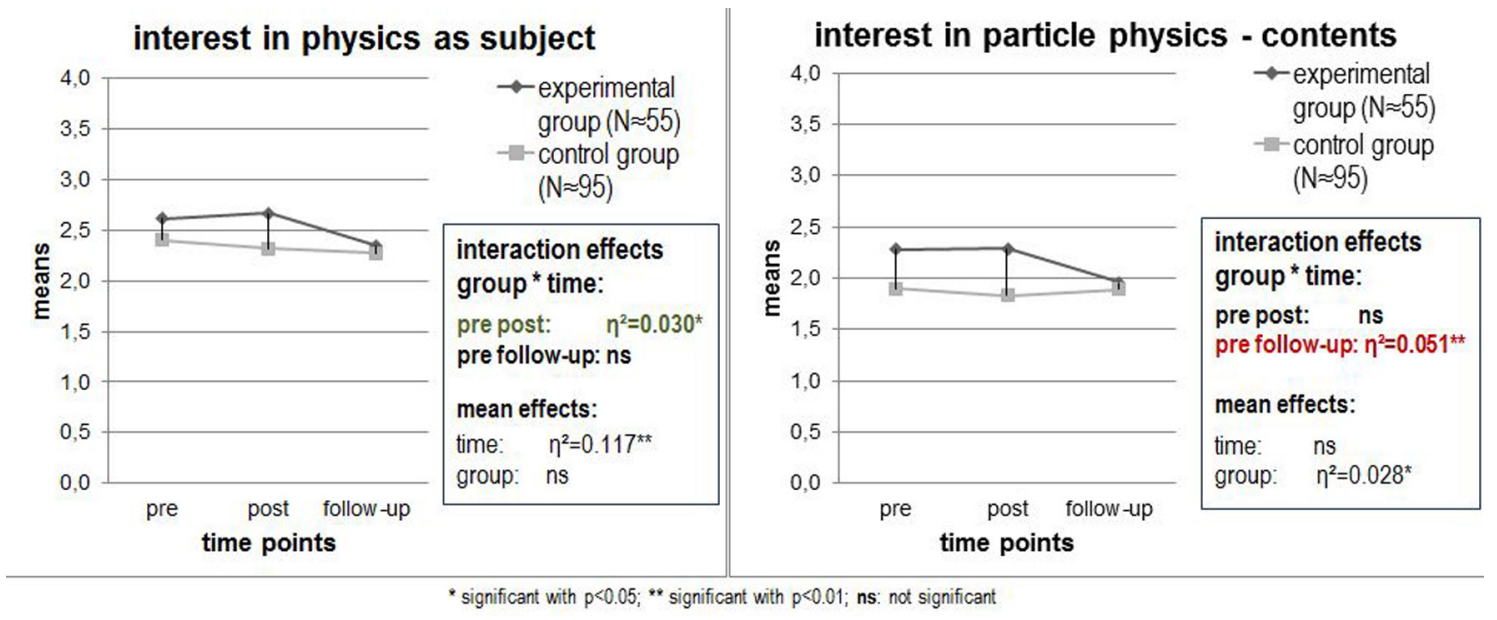

Figure 4: Analysis of variance with repeated measurements for the interest in physics as subject (left) and for the interest in the particle physics' contents (right) for classes 10

results of similar recent studies (Engeln, 2004; Pawek, 2009). It is noteworthy that the experimental group shows significant higher interest values in the pre- and posttest, whereas in the follow-up test the values of both groups are similar. It seems that the prospect of participating in a Masterclass causes an increase in the students' physics interests even before they started.

\section{THE INFLUENCE OF THE PERCEIVED EVENT FEATURES}

How the Masterclass' participants perceive the events was also part of the evaluation of the "experimental group". An overview is represented in Figure 5. All features are very positively perceived: they are rated higher than 2 by most participants. The best rated feature is "support and atmosphere", which shows that the young facilitators are able to create an agreeable learning environment. The second best rated feature is "authenticity" which indicates that the authentic setting is noticed as such by the students.

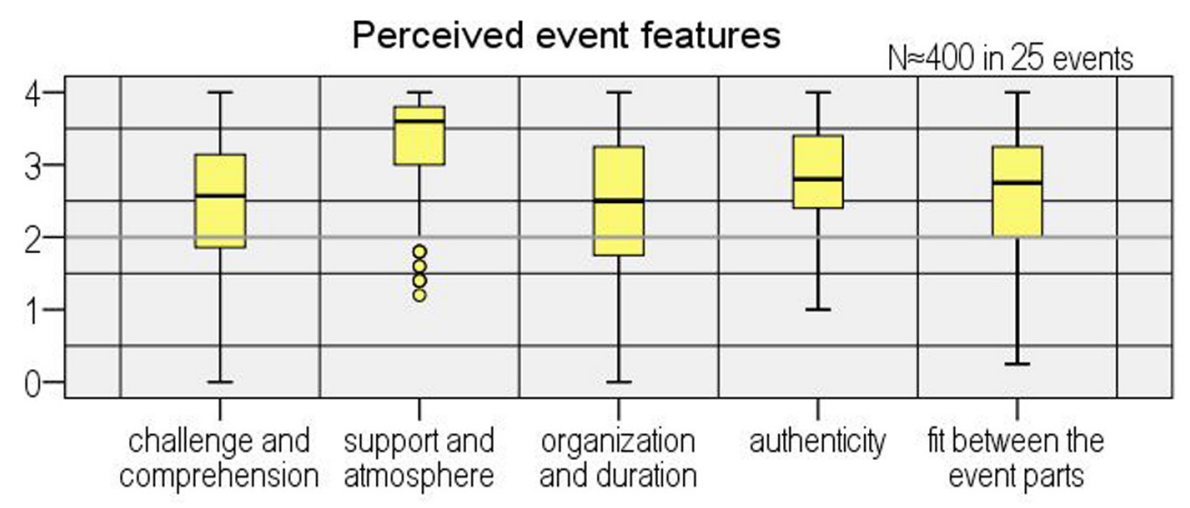

Figure 5: Masterclass' features as perceived by the "experimental group". The yellow boxes cover $50 \%$ of the students, the black lines cover $100 \%$, dots are outliers

Table 1 shows the influence of these perceived event features on the interests beyond the Masterclasses and the short- and long-term development of the particle physics' interest dimensions (also see Figure 6). "Support and atmosphere" and the "fit between the event parts" are excluded from the regression analysis, because of 
Table 1: Influence of perceived event features on students' interests - Multiple regression: standardized regression coefficients

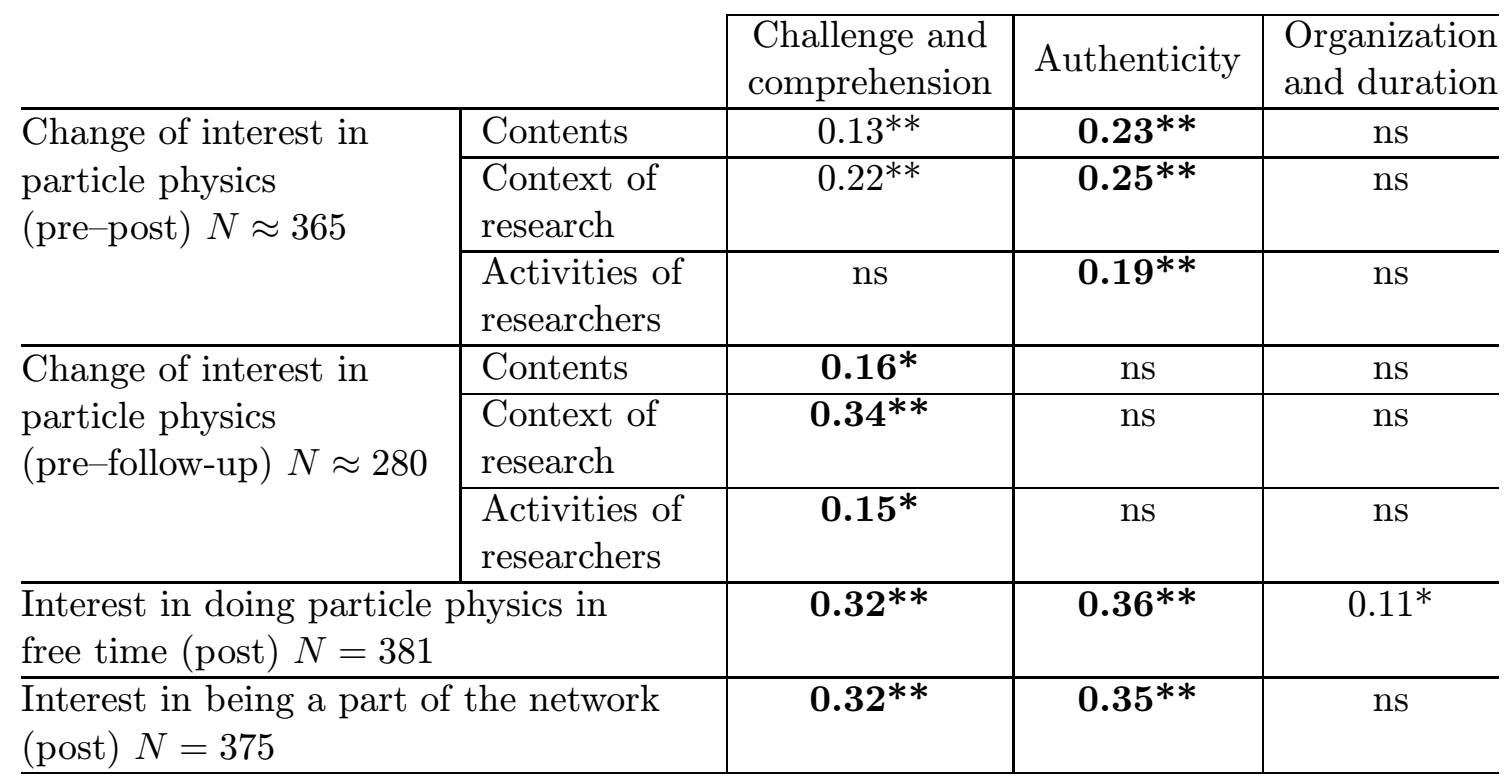

*significant with $p<0.05 ;{ }^{* *}$ significant with $p<0.01 ;$ ns: not significant

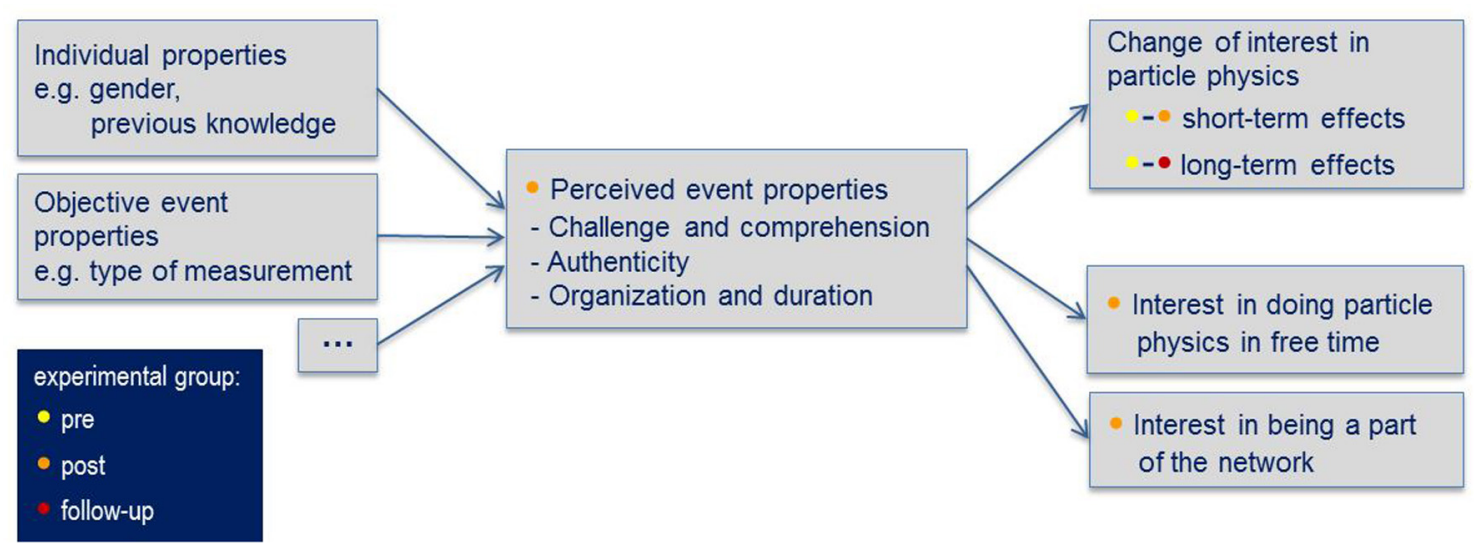

Figure 6: Influencing factors on perceived event features and their influence on interests

occurring multicollinearity effects (Rudolf \& Müller, 2012: p. 51-54). For determining the change of interests the difference of the interest values between the respective time points was used. The standardized regression coefficients show that "authenticity" has the most important influence on the short-term change of the interest in particle physics, "challenge and comprehension" on the long-term change and both of them are important for the interests beyond the Masterclass participation.

For deeper analysis we looked for possible influences on the perceived event features. On the one hand there are the individual properties of the students, which have an influence on the perception and on the other hand there are the objective event features (e.g. duration). Which of the selected factors shown in Figure 6 actually have an influence on the perceived event features is determined via MannWhitney-U-tests. Table 2 shows the corresponding results with the related effect sizes Cohen's d. It is defined as the difference between two means divided by the square root of their average variance (Bortz \& Döring, 2006: p. 606). The gender of the participants causes a medium effect size (Bortz \& Döring, 2006: p. 606) on 
both of the relevant features. Males rate the perceived features better than females. Furthermore, students with a higher prior knowledge in particle physics show a more positive rating of "challenge and comprehension" with a medium effect size and of "authenticity" with a small effect size. For the type of the measurement there is only a recognizable effect on "challenge and comprehension". This is not surprising, due to the fact that the LHC measurements are more difficult in comparison to the LEP measurements.

Table 2: Selected factors influencing the relevant perceived event properties

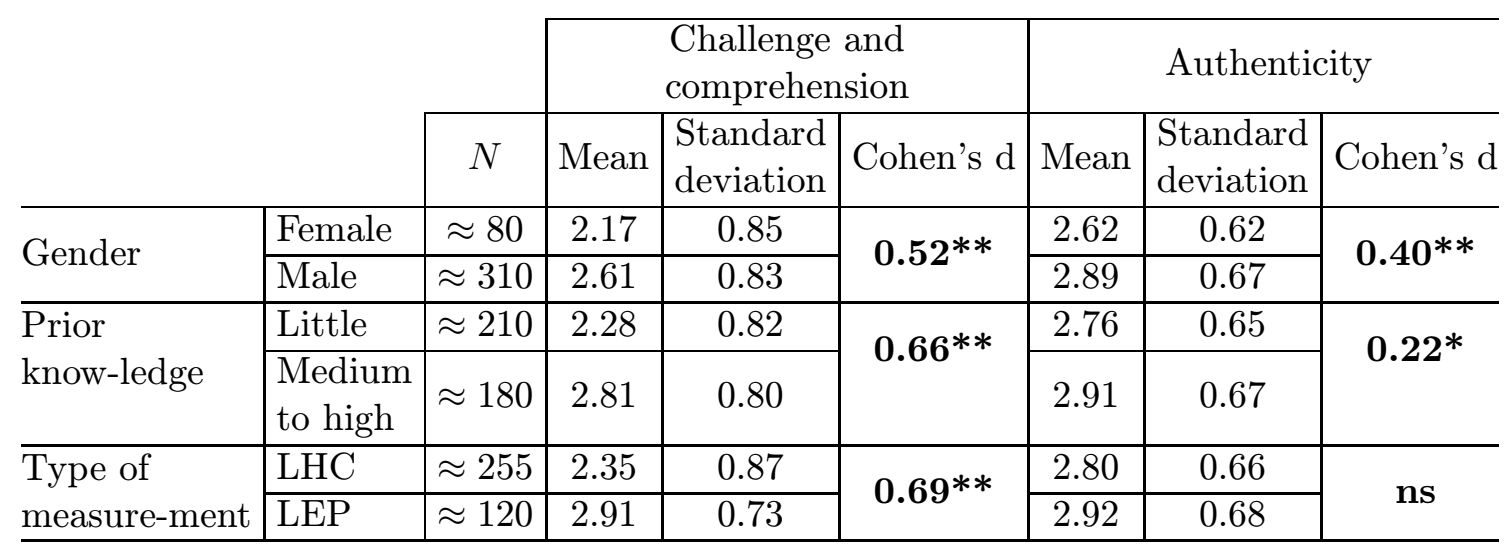

*significant difference between the groups (t-test and U-test) with $p<0.05$;

*significant difference between the groups (t-test and U-test) with $p<0.01$;

ns: not significant

\section{CONCLUSIONS AND OUTLOOK}

The participants' assessment via the perceived event features indicates that the Particle Physics Masterclasses are much appreciated by the students (cf. Figure 5). The comparison of the physics interests between "experimental group" and "control group" in class 10 shows a larger interest of the Masterclass' participants at the pre-test time. This difference disappears over the 6 to 8 week period. This corresponds to the expectation that one-time events like Masterclasses have only short-term effects on the students' interests. Recent studies of other one-time events show similar results (e.g. Engeln, 2004; Pawek, 2009). It implicates the question, if such interest differences appear for all the groups of Masterclass' participants (cf. Figure 3), which are still under study. Another question is to find a more detailed explanation for this interest difference between "experimental" and "control group".

The investigation of the influence of the perceived event features shows that "authenticity" as well as "challenge and comprehension" are important properties. Some selected factors which are influencing these perceived event features were illustrated. The effect of the participants' prior knowledge in particle physics, might indicate that a specific preparation of the event in physics lessons could be helpful. Especially concerning the objective event features there should be further factors identified, which have an influence on the perceived event features and thus consequently could improve the effect of the Masterclasses. 


\section{REFERENCES}

Bilow, U., Jende, K., Kobel, M. \& Pospiech, G. (2011). Das Konzept "Masterclass" Schüler beschäftigen sich mit dem LHC. In Praxis der Naturwissenschaften - Physik in der Schule, 60(2), 22-28.

Bortz, J. \& Döring, N. (2006). Forschungsmethoden und Evaluation. Heidelberg: Springer Verlag.

Engeln, K. (2004). Schülerlabors: authentische, aktivierende Lernumgebung als Möglichkeit, Interesse an Naturwissenschaft und Technik zu wecken. Berlin: Logos-Verlag.

Gedigk, K., Glück, A. \& Kobel, M. (2011). Netzwerk Teilchenwelt - Ein mobiler Lernort für Teilchenphysik. Praxis der Naturwissenschaften - Physik in der Schule, 60(2), 29-33.

Hoffman, L., Häußler, P. \& Lehrke, M. (1998). Die IPN-Interessenstudie. Kiel: IPN.

Johansson, K. E., Kobel, M., Hillebrandt, D., Engeln, K. \& Euler, M. (2007). European particle physics masterclasses make students into scientists for a day. In Physics Education, 42(6), 636-644.

Krapp, A. (1992). Das Interessenkonstrukt. In Krapp, A., Prenzel, M. (Eds.), Interesse, Lernen, Leistung (297-329). Münster.

Krapp, A. (2006). Interesse. In Rost, D. H. (Ed.), Handwörterbuch Pädagogische Psychologie (280-290). Weinheim: Beltz Verlag.

Pawek, C. (2009). Schülerlabore als interessefördernde außerschulische Lernumgebung für Schülerinnen und Schüler aus der Mittel- und Oberstufe [Dissertation].

Christian-Albrechts-Universität zu Kiel.

Rudolf, M. \& Müller, J. (2012). Multivariate Verfahren. Göttingen: Hogrefe Verlag.

\section{ANNEX}

Table 3: The relatively stable and the changeable interest variables (answer options:

(0) I totally disagree - (4) I totally agree)

\begin{tabular}{l|l|c|c}
\hline Variable & Examples for Items & $\begin{array}{c}\text { Number } \\
\text { of Items }\end{array}$ & $\begin{array}{c}\text { Cron- } \\
\text { bach's } \alpha\end{array}$ \\
\hline $\begin{array}{l}\text { Interest in physics as } \\
\text { subject }\end{array}$ & I enjoy physics lessons. & 4 Items & $\alpha=.861$ \\
\hline Self-Concept in physics & I don't have talent for physics. & 4 Items & $\alpha=.880$ \\
\hline $\begin{array}{l}\text { Interest in physics as } \\
\text { profession }\end{array}$ & $\begin{array}{l}\text { I can imagine to work in a profession, } \\
\text { which has something to do with physics. }\end{array}$ & 4 Items & $\alpha=.914$ \\
$\begin{array}{l}\text { Interest in doing particle } \\
\text { physics in free time }\end{array}$ & $\begin{array}{l}\text { I will spend more free time on particle } \\
\text { physics. }\end{array}$ & 4 Items & $\alpha=.862$ \\
\hline $\begin{array}{l}\text { Interest in being a part } \\
\text { of the network }\end{array}$ & $\begin{array}{l}\text { I plan to get involved in the "Network } \\
\text { Particle World". }\end{array}$ & 6 Items & $\alpha=.898$ \\
\hline
\end{tabular}


Table 4: The different particle physics interest dimensions (answer options: my interest is (0) very low - (4) very big) and of the perceived event features (answer options: (0) I totally disagree - (4) I totally agree)

\begin{tabular}{|c|c|c|c|c|}
\hline Variable & Dimensions & Examples for Items & $\begin{array}{l}\text { Number } \\
\text { of Items }\end{array}$ & $\begin{array}{c}\text { Cron- } \\
\text { bach's } \alpha\end{array}$ \\
\hline \multirow[t]{3}{*}{\begin{tabular}{l|} 
Interest \\
in particle \\
physics
\end{tabular}} & Contents & $\begin{array}{l}\text { what are the fundamental building } \\
\text { blocks of matter; what really is the } \\
\text { "Higgs" }\end{array}$ & 6 Items & $\alpha=.881$ \\
\hline & $\begin{array}{l}\text { Context of } \\
\text { research }\end{array}$ & $\begin{array}{l}\text { how research at CERN is organized; } \\
\text { which phenomena scientists still can't } \\
\text { explain }\end{array}$ & 7 Items & $\alpha=.835$ \\
\hline & $\begin{array}{l}\text { Activities of } \\
\text { researchers }\end{array}$ & $\begin{array}{l}\text { how physicists at CERN discuss } \\
\text { measurement results; how experiments } \\
\text { at CERN are performed }\end{array}$ & 5 Items & $\alpha=.877$ \\
\hline \multirow[t]{5}{*}{$\begin{array}{l}\text { Perceived } \\
\text { event } \\
\text { features }\end{array}$} & $\begin{array}{l}\text { Challenge and } \\
\text { comprehension }\end{array}$ & $\begin{array}{l}\text { The introductory presentation was too } \\
\text { complicated for me; The aim of the } \\
\text { measurement was clear to me. }\end{array}$ & 7 Items & $\alpha=.886$ \\
\hline & $\begin{array}{l}\text { Support and } \\
\text { atmosphere }\end{array}$ & $\begin{array}{l}\text { I liked the working atmosphere during } \\
\text { the measurement; I felt that the tutors } \\
\text { were helpful. }\end{array}$ & 5 Items & $\alpha=.846$ \\
\hline & Authenticity & $\begin{array}{l}\text { I got a feeling, how research is } \\
\text { conducted. } \\
\text { Today I learnt something about the } \\
\text { aims of physical research. }\end{array}$ & 5 Items & $\alpha=.786$ \\
\hline & $\begin{array}{l}\text { Organization } \\
\text { and duration }\end{array}$ & $\begin{array}{l}\text { The introductory presentation took too } \\
\text { long for me; I would have liked to } \\
\text { identify fewer events during the } \\
\text { measurement. }\end{array}$ & 4 Items & $\alpha=.774$ \\
\hline & $\begin{array}{l}\text { Fit between } \\
\text { the event } \\
\text { parts }\end{array}$ & $\begin{array}{l}\text { I felt prepared for the measurement } \\
\text { through the event identification } \\
\text { exercise. }\end{array}$ & 4 Items & $\alpha=.826$ \\
\hline
\end{tabular}

\section{KERSTIN GEDIGK}

Gesche Pospiech

Professur Didaktik der Physik, TU Dresden, Germany

MiChAel KOBEL

Institut für Kern- und Teilchenphysik, TU Dresden, Germany 